\title{
Colonia Augusta Firma. Consideraciones sobre su papel económico y político en su contexto fundacional ${ }^{\star}$
}

Salvador Ordóñez Agulla y Sergio García-Dils De La Vega

\section{Universidad de Sevilla}

sagulla@us.es / sergio.garcia.dils@me.com

Fecha recepción 22.02.2016 / Fecha aceptación 22.06.2016

\section{Resumen}

Se ofrece en este trabajo una aproximación a diferentes aspectos relativos a la fundación de colonia $\mathrm{Au}$ gusta Firma (Écija - Sevilla) y su identificación como ciudad del poder.

\section{Palabras clave}

Astigi, colonia, fundación, economía, poder

\section{Abstract}

The purpose of this research paper is to understand how and why colonia Augusta Firma (Ecija, Seville) was founded and identified as a "city of power".

\section{Key words}

Astigi, Colony, Foundation, Economy, Power.

* Este trabajo se ha redactado en el marco de los Proyectos de investigación $\mathrm{I}+\mathrm{D}+\mathrm{i}$ «Epigraphia astigitana. Instituciones, sociedad y mentalidades en colonia Augusta Firma (Écija - Sevilla) a la luz de la nueva evidencia epigráfica» [HAR2009-08823] $\mathrm{y}$ «Urbes en transformación. El paisaje urbano romano del Valle del Guadalquivir a través del análisis de las soluciones arquitectónicas: materiales, técnicas y esquemas productivos» [HAR2012-36963-C05-04], ambos financiados por el Ministerio de Ciencia e Innovación. 


\section{Introducción}

Entre las múltiples vertientes que contempla el estudio diacrónico de la ciudad y del territorio en época antigua, en general, y en la Hispania romana, en particular, una de las más complejas reside en establecer las implicaciones reales que tuvo la ambiciosa política colonizadora desarrollada durante el gobierno de Augusto. No pocas veces se aborda el estudio de las fundaciones coloniales dando por hecha la idoneidad de su emplazamiento y, como consecuencia directa de ella, su prosperidad, sin considerar hasta qué punto, en muchos casos, se trató de apuestas arriesgadas realizadas con una clara conciencia global del territorio que se quería explotar y administrar. La principal dificultad de este tipo de estudios radica en que requieren, como punto de partida, un conocimiento exhaustivo del territorio y del emplazamiento específico de las nuevas poblaciones en los siglos previos y posteriores a su creación, para valorar en su justa medida las transformaciones experimentadas por el territorio y ver si se configuró realmente un paisaje colonial netamente diferenciado de la situación precedente. Dicha información, analizada convenientemente, resulta además fundamental para concretar cómo se llevaron a cabo en la práctica las deductiones, procesos que, como se verá en las líneas que siguen, necesariamente tuvieron que ser costosos y prolongados en el tiempo en casos como el de colonia Augusta Firma.

Las reflexiones y conclusiones que se van a mostrar a continuación parten del estudio de los resultados de los trabajos realizados en el seno del denominado Proyecto AstiGIS ${ }^{1}$ que, vinculado institucionalmente al Departamento de Historia Antigua de la Universidad de Sevilla, nació en 1992 con el objetivo de abordar el estudio diacrónico de la ciudad y del territorio histórico de Écija ${ }^{2}$ desde la Protohistoria hasta la Baja Edad Media cristiana, con especial énfasis en la época romana, utilizando como soporte los Sistemas de Información Geográfi-

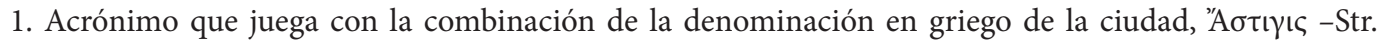

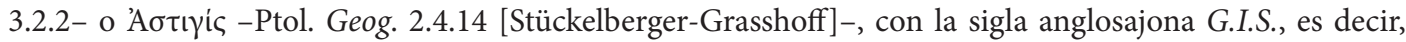
Geographic Information System.

2. El área de estudio del Proyecto se corresponde en líneas generales con la del iqlim de la madina de Istiyya, reconstruido sobre los límites establecidos en el Repartimiento de 1263, la más antigua demarcación conocida, y comprende un área de $1231,26 \mathrm{~km}^{2}$, con un perímetro de $145,16 \mathrm{~km}$, incluyendo completos los actuales términos municipales de Écija, La Luisiana y Cañada Rosal, así como parte de los de Marchena, Fuentes de Andalucía, Palma del Río, Fuente Palmera, La Carlota y Santaella. 
$\mathrm{ca}^{3}$. Fuera del ámbito estrictamente académico, los resultados de los trabajos de prospección y excavación arqueológicas en el territorio, realizados en el seno del Proyecto, han visto la luz gracias a su incorporación al planeamiento urbanístico de los términos municipales de Écija ${ }^{4}$, La Luisiana ${ }^{5}$ y Cañada Rosal $^{6}$, con lo que ello implica para la protección eficiente del Patrimonio Arqueológico rural.

En lo que se refiere a la ciudad, una de las vertientes iniciales del Proyecto consistió en abordar la recopilación sistemática de toda la evidencia arqueológica conocida, que, tras ser procesada y posteriormente analizada para establecer el estado de la cuestión, vio la luz ya entrado el nuevo siglo en el volumen urbano de la Carta Arqueológica Municipal de Écija ${ }^{7}$. Esta obra, ampliada, en cuanto a extensión documentada, gracias a las numerosas intervenciones arqueológicas urbanas realizadas en la década de 2000 y, en cuanto a nivel de detalle, merced a una aproximación de los resultados a escala intra-site, dará lugar a una tesis doctoral y posterior monografía con el estudio urbanístico de la ciudad antigua ${ }^{8}$. En fin, el

3. Cf. una aproximación metodológica en P. Sáez, S. Ordóñez, S. García-Dils, "Aplicaciones de los S.I.G. al territorio y casco urbano de Écija (Sevilla)", $3^{\circ}$ Congresso de Arqueologia Peninsular. Sistemas de Informaçao Arqueológica. SIG's aplicados à arqueologia da Península Ibérica, Porto, 2000, 15-42; S. García-Dils, S. Ordóñez, E. García, "Del territorio a la arqueología urbana. Una aplicación intra-site del Proyecto AstiGIS”, en J. C. Martín, A. M. Lucena (Coord.), Actas del I Congreso Internacional sobre Informática Aplicada a la Investigación y la Gestión Arqueológicas (5-7 de mayo de 2003), Córdoba 2004, 369-387; P. Sáez, S. Ordóñez, S. García-Dils, "Paisaje agrario y territorio en la campiña occidental de la Baetica", Arqueología espacial, 26, 2007, 143-170.

4. El Plan General de Ordenación Urbanística de Écija, que incluye la protección de 221 yacimientos arqueológicos, a los que hay que sumar 123 localizaciones más consignadas a efectos de inventario -yacimientos desaparecidos, duplicados o de dudosa ubicación-, fue aprobado definitivamente de forma parcial por Resolución de la Comisión Provincial de Ordenación del Territorio y Urbanismo de fecha 23 de octubre de 2009, con Documento Complementario aprobado por el mismo órgano en su sesión de fecha 14 de mayo de 2010.

5. El documento de Aprobación Provisional II del Plan General de Ordenación Urbanística de La Luisiana, que contempla la protección de 36 yacimientos, incluyendo 3 fichas más a efectos de inventario, fue aprobado en sesión extraordinaria del Pleno del Ayuntamiento con fecha 3 de abril de 2013. Actualmente se encuentra en vigor y a la espera de su aprobación definitiva.

6. Desde marzo de 2014 en trámite de segunda Aprobación Provisional, con un catálogo de 27 yacimientos arqueológicos protegidos.

7. P. Sáez, S. Ordóñez, E. García, S. García-Dils, Carta Arqueológica Municipal de Écija. 1. La ciudad, Sevilla 2004. En esta obra de síntesis se plantea la evolución de la ciudad desde sus orígenes, ca. siglo IX a.C., hasta la conquista cristiana y posterior repartimiento, en 1263, a partir del estudio de las 167 intervenciones arqueológicas realizadas hasta 2002, así como de 38 noticias orales y escritas sobre el particular, en su mayoría testimonios de hallazgos casuales recogidos por eruditos y cronistas locales desde el siglo XVII.

8. S. García-Dils, Colonia Augusta Firma Astigi. El urbanismo de la Écija romana y tardoantigua, Sevilla, 2015. Este estudio procesa y analiza 26 noticias documentales e historiográficas recogidas entre mediados del siglo XVI y 1950, así como 20 noticias orales y excavaciones arqueológicas de rescate entre los años 1951 y 1983, a las que se suma la información procedente de 501 actuaciones arqueológicas, de diferente 
procesado y análisis histórico de la documentación referida al territorio se ha plasmado en la redacción del segundo volumen de la Carta Arqueológica Municipal, dedicado al ámbito rural, documento cuya publicación por el momento no se ha materializado dadas las condiciones económicas en que las sobreviven las instancias públicas?.

\section{La prouincia Baetica y sus conuentus iuridici}

Llegado el último cuarto del siglo I a.C., en la recién creada prouincia Baetica, prouincia populi Romani, un territorio pacificado en el que habían pasado a un segundo plano las cuestiones estrictamente militares, resulta palpable que el poder romano toma conciencia de la necesidad de administrar eficientemente este territorio intensivamente poblado y rico en recursos de todo tipo, desarrollando mecanismos para la plena integración en los modelos de Roma ${ }^{10}$. Entre las medidas adoptadas en este sentido para completar la construcción provincial, cabe incluir el establecimiento de cuatro conuentus iuridici ${ }^{11}$. Tres de ellos tendrían su sede en ciudades que ya contaban con un importante peso específico en cuanto al control del territorio y habían tenido un papel protagonista durante la época tardorrepublicana. Gades, Hispalis y Corduba eran en ese momento ciudades consolidadas, prácticamente equidistantes y unidas por las principales vías de comunicación terrestre, la uia Augusta, y fluvial, el Baetis, por lo que su elección como sedes conventuales no dejaba de ser obvia y prácticamente

alcance, llevadas a cabo desde 1984 a 2015, lo que eleva a 547 los espacios urbanos de los que se cuenta con información arqueológica.

9. Dentro de este ámbito territorial, hasta la fecha se ha identificado, delimitado y caracterizado un total de 284 yacimientos arqueológicos, vid. P. Sáez, S. Ordóñez, S. García-Dils, Carta Arqueológica Municipal de Écija. 2. El territorio, Sevilla, e.p.

10. P. Le Roux, La Péninsule Ibérique aux époques romaines. Fin du IIIe s. av. n. è. - début du VIe s. de n.è., Paris, 2010. Para un acercamiento global a la Baetica, vid. por ejemplo, A. T. Fear, Rome and Baetica. Urbanization in Southern Spain c. 50 BC-AD 150, Oxford, 1996; E. W. Haley, Baetica felix. People and prosperity in southern Spain from Caesar to Septimius Severus, Austin, 2003.

11. Hay que valorar con mesura las implicaciones reales de esta división que, como acertadamente ha señalado P. Le Roux, no dejaban de ser circunscripciones administrativas de función esencialmente judicial, pero sin instituciones propias -asambleas, magistrados, finanzas, reglamentos...-. Se trata, efectivamente, de circunscripciones judiciales, destinadas a facilitar el ejercicio de la justicia por parte del gobernador, a la resolución de litigios que sobrepasaban las competencias de la autoridad local y demostrar, de paso, la atención que Roma prestaba a los intereses privados de los ciudadanos. De este modo, y como se argumentará en adelante, estimamos que el criterio para ubicar las sedes -mejor que «capitales», término que quizá peca de anacrónico- de las reuniones de las asambleas en estas circunscripciones, era fundamentalmente el de la accesibilidad. P. Le Roux, "La question des conventus dans la péninsule Ibérique d'époque romaine", en $\mathrm{Au}$ jardin des Hespérides. Histoire, société et épigraphie des mondes anciens, Rennes, 2004, 337-356; P. Le Roux, "Regards augustéens sur les Gaules et la Péninsule Ibérique ou le récit d' une construction provinciale", en Hispania et Gallia. Dos provincias del occidente romano, Barcelona, 2010, 33-47, cit. 44-45. Se puede señalar, además, la elocuente ausencia de cualquier mención epigráfica a los conuentus de la Baetica, a diferencia de la vecina Tarraconensis. 
automática. Esta promoción administrativa supondrá, como es sabido, la plasmación de la superioridad de las sedes de los tribunales en la jerarquía de ciudades provinciales, sin que sea posible asignarle, sin embargo, un papel especial como fórmula de vertebración ${ }^{12}$.

Se puede proponer que es en época de Augusto cuando se toma conciencia de la existencia de un vasto territorio interior, de gran riqueza agrícola, cuyas únicas características comunes eran que se trataba de amplias áreas de vega y campiña, de gran riqueza agropecuaria, y constituían la cuenca hidrográfica del principal afluente del Baetis, el río Genil o Singilius ${ }^{13}$, que cobrará a partir de entonces un inédito protagonismo al ser una vía navegable. En este amplio territorio ${ }^{14}$, solamente podría haberse considerado a priori a Vrso como candidata a albergar la sede conventual, por su entidad urbana y por haberse establecido en su solar, de la mano de Julio César, la colonia Genetiua Iulia ${ }^{15}$. Sin embargo, jugaban en su contra precisamente las dos circunstancias favorables que se han señalado en relación con las otras tres ciudades: se encontraba alejada de la principal arteria de comunicación terrestre y de cualquier vía fluvial.

Vinculamos la fundación de colonia Augusta Firma precisamente a la toma de conciencia de la importancia del Genil como vía navegable potencial, río que no contaba con ninguna ciudad de consideración instalada en sus orillas, así como de su cuenca hidrográfica, concretamente los últimos $60 \mathrm{~km}$ de su curso, como territorio propicio para desarrollar una actividad agrícola e industrial a gran escala. Esta toma de conciencia, que implicaba una visión global del territorio que se iba a administrar basada en la práctica y la experimentación concretas, llevó a plantear la necesidad de fundar la ciudad en un enclave que permitiera a la futura colonia representar un papel análogo al de las otras tres sedes conventuales, como ciudad-puente / ciudad-puerto, con doble control de las principales vías de comunicación terrestres y navegables, lo que suponía contar con una óptima accesibilidad. Su papel como sede del conuentus Astigitanus, por tanto, sería resultado directo de la idoneidad de su emplazamiento ${ }^{16}$.

12. Vid. A. Caballos Rufino, "La Bética como referente identificador en la documentación epigráfica", en A. Caballos Rufino, S. Lefebvre (eds.), Roma generadora de identidades. La experiencia hispana, Madrid, 2011, 185-207, cit. 189-190.

13. La denominación comúnmente aceptada, Singilis, se basa únicamente en la autoridad de Plinio -NH 3.12-, mientras que otros autores, geográfica o temporalmente más cercanos, como Isidoro de Sevilla, lo mencionan como Singil(l)ius. Para una argumentación sobre el particular, vid. P. Sáez, S. Ordóñez, S. García-Dils, "Infraestructuras hidráulicas en el territorio de una colonia romana de la Bética: el caso de Astigi, colonia Augusta Firma (Écija, Sevilla, España)", en Aquam perducendam curavit. Captación, uso y administración del agua en las ciudades de la Bética y el Occidente romano, Cádiz, 2010, 411-438, cit. 412-416.

14. Basándonos en las propuestas comúnmente aceptadas, como la que se presenta en $C I L \mathrm{II}^{2} / 5$, se puede calcular la extensión de los territorios incluidos en el conuentus Astigitanus en torno a los $16000 \mathrm{~km}^{2}$.

15. A. Caballos Rufino, El nuevo bronce de Osuna y la política colonizadora romana, Sevilla, 2006, para todos los aspectos relativos a una fundación colonial cesariana.

16. Tal como se ha argumentado supra, creemos que escapa a la lógica de la administración romana considerar que la ciudad se fundara como «capital» administrativa de este extenso territorio, sino que el 
Aunque pudiera resultar una obviedad, en relación con la nueva colonia y su ubicación en el valle del Genil, hay que insistir en que se funda en un momento en el que el poder romano contaba, en la práctica, con una total libertad de movimientos para fundar una ciudad allí en donde resultase de mayor utilidad, prescindiendo de los condicionantes geopolíticos que habían tenido un mayor protagonismo en épocas anteriores y que ahora, en una provincia en paz, ya no eran relevantes. No se trataba ya, por tanto, de reforzar la presencia romana en un entorno hostil, ni de instalar una colonia de castigo a la usanza cesariana, sino de administrar eficientemente un rico territorio y ponerlo a producir dentro del conjunto de la maquinaria del Imperio.

La colonia se fundará en el punto preciso en el que el río Genil, que discurre prácticamente encañonado desde su nacimiento en Sierra Nevada, se abría a un valle, facilitando su vadeo y posibilitando su navegabilidad, donde se encontraba en aquel momento un pequeño asentamiento indígena, Astigi, instalado sobre un promontorio elevado localizado aguas abajo del encuentro entre el río Genil y un afluente secundario, el arroyo de la Argamasilla (Plin. H.N. 3.12) ${ }^{17}$.

La posterior prosperidad de colonia Augusta Firma y su importante papel en los siglos venideros podría fácilmente engañarnos en cuanto a la situación de partida con la que se encontraron los futuros pobladores en el momento de su fundación. En primer lugar, se trataba de una zona deprimida localizada en la confluencia entre un río de régimen pluvional y un arroyo con una importante cuenca de captación, que convertía el entorno inmediato de Astigi en una zona expuesta a continuas y bruscas inundaciones, situación que había impedido secularmente a la ciudad extenderse más allá del pequeño promontorio donde se hallaba instalada, de apenas 8,5 ha, convirtiéndose a menudo en una verdadera isla ${ }^{18}$. Además, en

convertirse en sede conventual no sería más que resultado de su status colonial y su buena comunicación tanto con la capital provincial, como con las demás sedes y el ámbito del conuentus.

17. Sobre las circunstancias de la fundación de la colonia y la caracterización de este núcleo indígena, así como la espinosa cuestión de su identificación con la Astigi Vetus de Plinio, vid. S. García-Dils, "Colonia Augusta Firma Astigi (Écija, Sevilla). La estructura urbana de una fundación romana en la Baetica", en J. González, J. C. Saquete (eds.), Colonias de César y Augusto en la Andalucía romana, Roma, 2011, 99-128; en contra de esta adscripción, vid. A. U. Stylow, "Die Accitani veteres und die Kolonie Iulia Gemella Acci. Zum Problem von veteres, Alt-Stadt und Kolonie in der Hispania Ulterior", Chiron, 30, 2000, 775-806.

18. Esta dinámica sigue siendo habitual en el término municipal de Écija, donde numerosos enclaves se quedan a menudo aislados por las aguas, con elocuentes topónimos como «isla del Castillo», «isla del Vicario» o «isla Redonda», esta última una pequeña población con categoría de Entidad Local Autónoma (ELA) dependiente de Écija. Ése podría ser el origen del topónimo Astigi, ya que, según ha apuntado F. Villar en Indoeuropeos y no indoeuropeos en la Hispania prerromana, Salamanca, 2000, 67, 78, 80-81, 249256, 281-283, 288, 302-303, 353-354, 383-384, considerando -igi como posible apelativo no indoeuropeo, propio del sur de la Península, con significado de «ciudad, pueblo, aldea», relacionando Ast- con la raíz indoeuropea *as- «estar seco», se configuraría un topónimo con el sentido de «lugar poblado que está seco», próximo a un curso de agua. Cabe mencionar al respecto que en España hay más de una decena de poblaciones de nombre «Villaseca». 
aquel momento, como se desprende de Bell. Alex. 57, la que será denominada uia Augusta ${ }^{19}$ discurría a $10 \mathrm{~km}$ hacia el noroeste de Astigi, prácticamente en línea recta desde Obulcula en dirección a Corduba, atravesando el río Genil por el oppidum que se ha identificado como Segouia, situado en la isla del Castillo. Por último, se trataba de una posición indefendible desde el punto de vista militar, sumida en el fondo de una depresión rodeada de colinas, lo que solamente hacía viable que prosperase la colonia en una provincia pacificada y no sujeta a incursiones militares ${ }^{20}$.

Estas circunstancias desfavorables implican que la decisión de fundar aquí la colonia destinada a convertirse en sede conventual, en absoluto obvia, se basaba en un conocimiento global del territorio en el que se quería intervenir, considerando la perspectiva a largo plazo de que una actuación urbanística y territorial planificada acabaría compensando estas deficiencias, todo en aras de la administración eficiente de los recursos agrícolas que brindaba la campiña astigitana. Todo el proceso, en fin, era resultado de la cuidadosa evaluación por el princeps, y más concretamente, del deductor coloniae, de las condiciones estratégicas y económicas que ofrecía potencialmente el lugar seleccionado para la fundación.

En conclusión, estimamos que la fundación de la colonia constituía una apuesta arriesgada por parte del poder romano, pues su viabilidad implicaba una importante inversión inicial de recursos humanos y económicos. Se puede decir, en este sentido, que la conciencia de colonia Augusta Firma como «ciudad del poder» existía ya desde antes de su fundación, ya que, como se verá en las líneas que siguen, solamente a partir de una intervención directa del Estado se podía convertir en el plazo de unos 50 años un espacio casi inhabitable en una próspera ciudad de 55 ha con una implantación urbanística superior a las 100 ha, con capacidad de exportar su producción olearia a gran escala tanto a la Vrbs como a las principales ciudades y destacamentos militares del Imperio occidental.

\section{La deductio y sus implicaciones}

Tradicionalmente, la investigación ha manejado dos horquillas temporales en cuanto a la fecha de fundación de colonia Augusta Firma. O bien entre 25 y 19 a.C., próxima a la de Eme-

19. Tal y como queda reflejado en varios miliarios de las cercanías de Corduba, se trataba de una uia militaris -P. Sillières, Les voies de communication de l'Hispanie méridionale, Paris, 1990, 783-790; M. A. Speidel, "Heer und Strassen - Militares viae", Siedlung und Verkehr im römischen Reich. Römerstrassen zwischen Herrschafts sicherung und Landschaftsprägung, Bern, 2004, 331-344-, es decir, de una de las grandes calzadas públicas empleadas por funcionarios estatales y militares para su desplazamiento, uno de los ejes básicos en la estructuración estatal y en el sistema de comunicaciones entre la capital imperial y los administrados.

20. Por no hablar, además, del deficiente control visual del territorio que circundaba a la ciudad, circunstancia que ha podido determinarse de forma específica para época medieval, vid. García-Dils, Márquez, S. Ordóñez, loc. cit., 2000, 85-101. 
rita Augusta con la que comparte la adscripción de sus ciudadanos a la tribu Papiria ${ }^{21}$, o bien entre 16 y 14 a.C., con motivo de la tercera estancia de Augusto en Hispania ${ }^{22}$. Más recientemente, el hallazgo y publicación de un epígrafe funerario, mencionando a un eme(ritus) ex Legione Classica, presumiblemente uno de los colonos fundadores, permite concretar que la deductio tendría lugar entre los años 23 y 22 a. $C^{23}$. En cualquier caso, el episodio de la fundación es coincidente con las fechas en las que se crea la provincia Baetica, desgajada de la antigua Prouincia Hispania Vlterior. La documentación epigráfica muestra que, verosímilmente, la deductio colonial se realizó con veteranos militares, procedentes de las legiones XXX ó XVII Classica, IV Macedonica, VI Victrix y II Pansiana ${ }^{24}$.

El contingente poblacional que iba a habitar la ciudad necesariamente tuvo que recibir algún tipo de estímulos, ya que mientras a otros veteranos se les enviaba a ciudades consolidadas como Hispalis o Corduba, aunque ciertamente afectadas por los acontecimientos bélicos, los colonos astigitanos estaban destinados a vivir durante un par de generaciones en una ciudad en construcción, ya que se les asignaba un entorno hostil desde el punto geográfico, cuyas futuras ventajas reales sólo podían apreciarlas las élites administrativas del Imperio. Uno de los incentivos debió de ser, por ejemplo, la immunitas a la que indirectamente se refiere Plinio (H.N. 3.12) al mencionar las reliquae coloniae immunes.

Presumiblemente, la nueva comunidad civil se organizaría inicialmente de acuerdo a criterios militares, de manera que las magistraturas coloniales serían desempeñadas por los mandos de las legiones instaladas aquí, haciéndose el reparto de lotes de tierra en función de la graduación de los colonos ${ }^{25}$.

Dejando claro que, tal como se deduce de los resultados de las excavaciones arqueológicas y estudios paleogeográficos realizados en la ciudad, el esquema de poblamiento no

21. J. González, "De nuevo en torno a la fundación de la colonia Astigi Augusta Firma”, Habis, 26, 1995, 281-293, propone como fecha más probable la de 25 a.C.

22. L. Keppie, Colonisation and Veteran Settlement in Italy. 47-14 B.C., London, 1983, 17 y 83; S. Ordóñez: Colonia Augusta Firma Astigi, Écija, 1988, 46-47. Sobre las visitas del Princeps a la Península, vid. J. M. Abascal, "Los tres viajes de Augusto a Hispania y su relación con la promoción jurídica de ciudades", Iberia, 9, 2006, 63-78.

23. A. Ventura Villanueva, "Nuevos datos sobre la cronología de la deductio de Augusta Firma Astigi y sus colonos veteranos", Romula, 14, 2015, 7-27.

24. Ordóñez, op. cit., 1988, 46-50; González, loc. cit.,1995; P. Sáez, S. Ordóñez, E. García, S. García-Dils, "Cinco inscripciones romanas inéditas de Écija (Sevilla)", Habis, 32, 2001, 337-352.

25. Cuestión de la que sería buen ejemplo la inscripción de L. Caninio -AE 2001, $1204=H E p$ 11, 457-, uno de los genearcas de la colonia; A. Caballos, "Genearcas en los procesos de integración del Bajo valle del Baetis", en Hiberia-Italia Italia-Hiberia, Milano 2006, 407-431, cit. 424. Tácito esboza una breve pero elocuente semblanza de cómo eran -idealmente- las fundaciones militares en la época en la que realizó la deductio astigitana -Ann. 14.27-, mientras que el desigual reparto de tierras en estos casos es mencionado explícitamente por Higino Gromático -De lim. const. 176La- y Sículo Flaco -De cond. agr. 156.9-13La-. Vid. J. C. Saquete, "Del mundo militar al mundo civil: los veteranos militares y algunas colonias de Augusto en Hispania”, en J. J. Palao (Ed.), Militares y civiles en la antigua Roma: dos mundos diferentes, dos mundos unidos, Salamanca 2010, 79-92. 
pudo ser el de un «campamento militar» que paulatinamente evolucionara a ciudad, ya que se trataba de un enclave inhabitable a corto plazo, la cuestión clave que cabe plantear es cómo se realizó en la práctica el asentamiento de los colonos ${ }^{26}$. A escala territorial, para empezar, era necesario realizar toda una serie de actuaciones encaminadas a facilitar la implantación de la colonia. Así, se desvió el trazado de la uia Augusta para hacerla pasar por la naciente ciudad y, verosímilmente, se acondicionaron las márgenes del río Genil para facilitar la prolongación de su navegabilidad hacia el sur, lo que se traduciría a medio plazo en la conversión de Astigi en una verdadera ciudad-puente. La construcción de esta infraestructura marcaba precisamente la formalización en el espacio de uno de los símbolos, junto con la calzada, del nuevo poder. Sin embargo, la pregunta clave es cómo se programó el asentamiento de los colonos al tiempo que se trabajaba en la preparación del terreno para la construcción de la futura ciudad. Se trataba de un problema más que real, pues puede calcularse, en línea con otras deductiones augusteas, que se trataría de entre 2000 y 4000 pobladores, o incluso más ${ }^{27}$.

El estudio de los materiales recuperados en prospecciones arqueológicas en el entorno de Écija sugiere la existencia de una colonización previa, vinculada a la explotación de recursos estratégicos como canteras y sal, cuya cultura material es claramente de tradición tardorrepublicana y reminiscencias itálicas, mientras que los materiales excavados en la propia ciudad son ya propiamente augusteos. Concretamente, el área poblada en estas décadas de transición se extiende hacia el sureste de la colonia, donde se ha documentado un área centuriada que incluye las mencionadas salinas y canteras ${ }^{28}$. Entre los hallazgos arqueológicos localizados dentro de este ámbito, se puede destacar un friso dórico perteneciente a un monumento funerario de tradición itálica - probablemente colocado en un edificio turriforme, constituyendo un ejemplo de los elementos de autorrepresentación empleados por las familias de raigambre itálica- ${ }^{29}$ y una serie de estelas epigráficas de cabecera semicircular, con campo epigráfico rehundido y sin mención de tribu ni fórmula $D \cdot M \cdot S^{30}$. La primera de ellas menciona a un M(arcus) Aninius Adgouilus oriundus ab Aquis ex Gallia ${ }^{31}$, lo que es compatible con un ambiente que podría denominarse como pre-colonial. Las otras dos

26. Vid. Caballos Rufino, op. cit. 2006, 362 ss., para los pasos concretos del largo y complejo proceso de formalización de la deductio-adscriptio, deductio, sortitio-.

27. P. A. Brunt, Italian Manpower. 225 B.C.-A.D.14, Oxford, 1971, 238, 259-261: 2000-3000; Keppie, op. cit. 1983, 98: 3000-4000; según Augusto ( $R G$ 15.28), hasta el 29 a.C., él mismo asentó 120000 veteranos en 28 colonias lo que daría una cifra media de 4285 colonos en cada una.

28. Vid. infra.

29. J. Beltrán, S. Ordóñez, “Un friso dórico funerario de El Guijo (Écija, Sevilla)”, Habis, 35, 2004, $233-255$.

30. Las dos primeras inscripciones fueron halladas en el yacimiento denominado Salinas de la Torre 3, con el código [41.039.1239] en la Carta Arqueológica Municipal de Écija, y se conservan actualmente en la colección arqueológica de la iglesia de Santa María de Écija. Por sus características formales, puede adscribirse también a este yacimiento la tercera inscripción, de procedencia desconocida, aunque localizada también en este entorno; vid. J. Hernández Díaz, A. Sancho Corbacho, F. Collantes de Terán, Catálogo arqueológico y artístico de la provincia de Sevilla, Sevilla 1951, t. 3, 88-89.

31. CIL II ${ }^{2} / 5,1153$ = CILA II.3, 714. Cf. Adgubillus en la Narbonense, CIL XII 3042.

Revista de Historiografía 25, 2016, pp. 191-217 


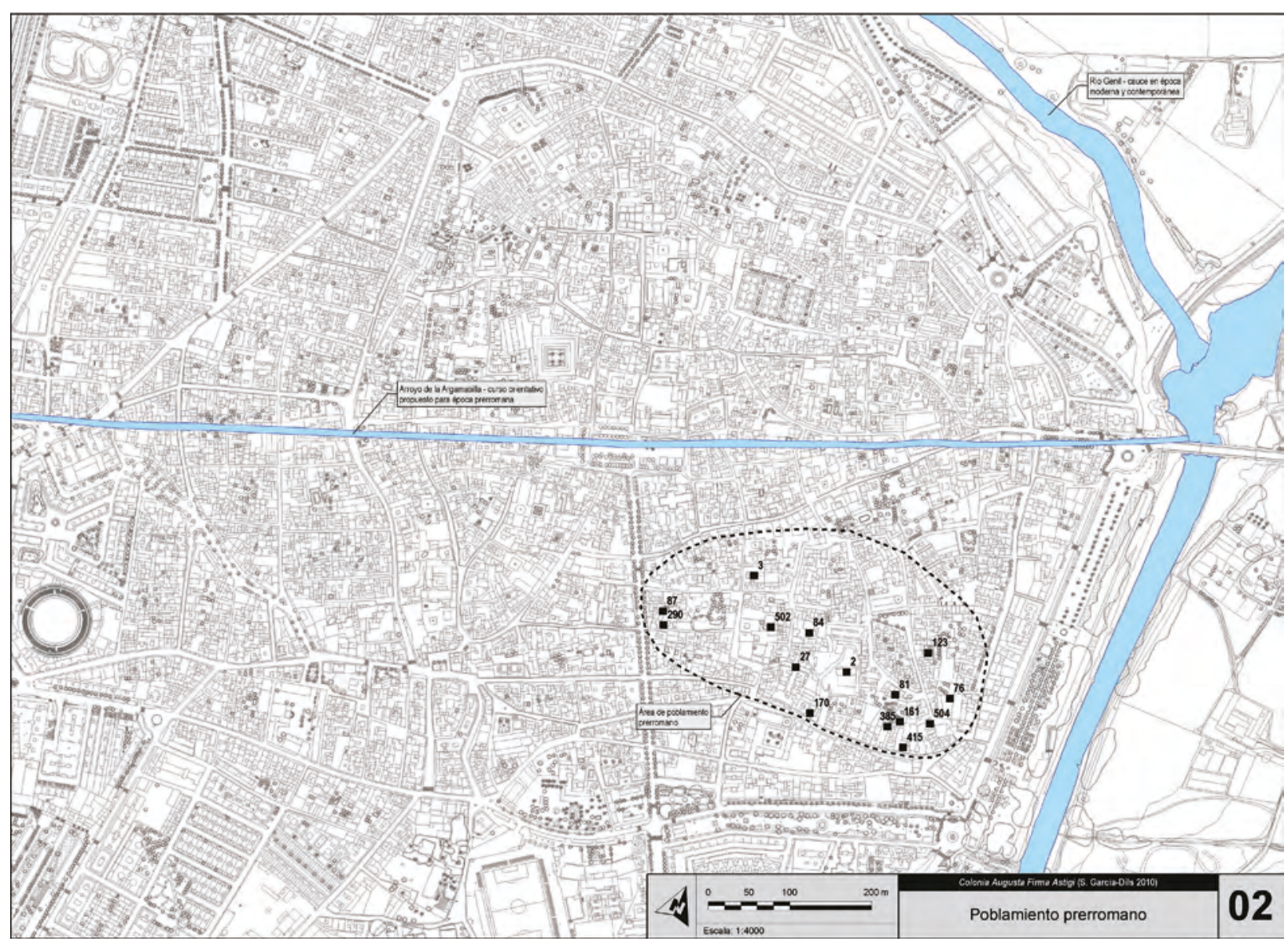

Fig. 1. Hipótesis de delimitación de Astigi Vetus en época turdetana.

se refieren, respectivamente, a un $L$ (ucius) Aninius, posiblemente hijo del anterior ${ }^{32}$, y a un $D$ (ecimus) Cornelius $M\left(\right.$ a)rcellus ${ }^{33}$.

\section{Astigi Vetus y la fundación de la ciudad}

En el estado actual de la investigación, no ofrece lugar a dudas la existencia de un núcleo indígena anterior a la fundación romana, ubicado en el sector suroriental de la futura colonia, con

32.CIL II $\mathrm{I}^{2} / 5,1154=$ CILA II.3, 713.

33.CIL II $/ 5,1155=$ CILA II.3, 734 . 
ocupación estable desde el siglo IX a.C. hasta el mismo momento de la deductio ${ }^{34}$. Las intervenciones arqueológicas desarrolladas en el área han probado que dicho núcleo tuvo en época turdetana una cierta entidad, toda vez que se ha documentado un buen número de edificaciones construidas con mampostería y algunos espacios productivos, como por ejemplo hornos cerámicos y áreas de extracción de materiales de construcción ${ }^{35}$. La georreferenciación de toda esta información permite proponer con fundamento que el espacio poblado ocupaba, en su momento de máxima expansión, una extensión de por lo menos 8,5 ha [Fig. 1].

El oppidum se ubicaba sobre un promontorio, el denominado actualmente cerro del Alcázar o de San Gil, localizado inmediatamente aguas arriba de la confluencia de dos cursos fluviales, el río Genil y el primitivo curso del arroyo de la Argamasilla, en una posición topográfica que, a primera vista, parece apartarse de la norma, si se compara con los demás núcleos de población protohistóricos conocidos en los valles del Guadalquivir y del Genil $^{36}$. A menudo se ha querido ver este oppidum turdetano como un núcleo secundario, partiendo de dos argumentos indirectos, como son la ausencia de amonedaciones ${ }^{37}$ y el que no aparezca citado en ninguno de los episodios bélicos de las guerras civiles cesarianas, y esto a pesar de haberse desarrollado en el entorno inmediato hechos de armas fundamentales, recogidos con detalle en las fuentes literarias conservadas ${ }^{38}$. En cualquier caso, no parece que se tratara de un centro de poder indígena relevante y con poderosas oligarquías que llamaran la atención de las fuentes romanas, al contrario de otros lugares como Obulco, Castulo o, más cerca, Carmo.

Desde el punto de vista arqueológico, se constata ampliamente que se trató de una fundación realizada ex nouo, haciendo tabla rasa de las estructuras indígenas previas, sin que se haya documentado ningún indicio de convivencia entre estructuras turdetanas y romanas ${ }^{39}$. Toda edificación o estructura previa quedó arrasada, por lo que se podría decir que se trató de una implantación traumática desde la óptica de la evidencia material. Conscientes de la escasa calidad geotécnica del terreno en el que se instalaba la ciudad, en su mayor parte conformado por rellenos aluviales, y el problema real que constituía la presencia de dos cursos

34. E. Rodríguez González, Astigi Vetus. Arqueología y urbanismo de la Écija turdetana (ss. VI-I a.C.), Madrid 2014.

35. García-Dils, loc. cit. 2011, 101-104.

36. L. A. López Palomo, El poblamiento protohistórico en el valle medio del Genil, Écija, 1999, 141.

37. García-Dils, loc. cit. 2011, 102 n. 13.

38. Sí se citan en cambio Obulcula y Segouia-Auct. B. Alex. 57.3 y 6-, situadas respectivamente al oeste y norte de Écija, y Carruca-Auct. B. Hisp. 27.5-6-, localizada al sur, si se acepta la identificación de Munda con el importante yacimiento de carácter urbano detectado en el cerro de Consuegra (Osuna, Sevilla); vid. bibliografía al respecto en P. Sáez, S. Ordóñez, S. García-Dils, "Colonias romanas y municipalización flavia. ¿Conflicto de intereses?”, en J. Mangas, M. Á. Novillo (eds.), El territorio de las ciudades romanas, Madrid, 2008, 155-175, cit. 156, n.7. Sobre la ausencia de Astigi en estas fuentes, cabe argumentar que solamente se citan las poblaciones directamente involucradas en los enfrentamientos; cf. Ordóñez, op. cit. 1988, 42-43.

39. Lo que descarta la existencia aquí de una «dípolis», en la que conviviera la Astigi Vetus indígena con una hipotética Astigi Noua romana, como han sugerido algunos autores. Cf., por ejemplo, la opinión de Hübner en RE 2.1790 s.u. Astigi. 
de agua en las inmediaciones, los nuevos pobladores acometieron un ambicioso programa de construcción de infraestructuras de todo tipo. Así, después de establecerse la delimitación de la futura colonia, se abordó una mejora y regularización general del terreno a poblar, rebajándose y aterrazándose las zonas más elevadas, donde se ubicaba la Astigi indígena, a la vez que se rellenaron las áreas más deprimidas, en las que incluso se construyeron infraestructuras subterráneas de contención de tierras ${ }^{40}$. Simultáneamente, se emprendió la construcción de la red viaria ${ }^{41}$, saneamiento ${ }^{42}$ y — cabe esperar- de la muralla ${ }^{43}$. Este primer impulso colonizador marcará el futuro devenir urbanístico de la colonia, hasta el punto de poderse afirmar que, en lo tocante a las infraestructuras principales, lo que no se haga a lo largo del primer siglo de existencia de la ciudad, después no se hará en el futuro.

El planteamiento general de la fundación de la colonia se basó, por tanto, en adaptar la topografía a las necesidades de la ciudad, y no al contrario, de manera que se soslayó en la medida de lo posible cualquier condicionante geográfico. Esta planificación cuidadosa de la ciudad implicó, como aspecto negativo, que fue necesario realizar movimientos de tierras de gran envergadura en el amplio sector de la futura colonia que se encontraba originalmente en el fondo de la llanura aluvial. Así, en el foro y el temenos ${ }^{44}$, que cubrían una extensión conjunta de $18.048 \mathrm{~m}^{2}$, se han detectado sucesivos niveles apisonados de rellenos con una potencia media de 1,5-2,0 m, aportados durante un período que se puede calcular en unos 50 años a juzgar por los materiales cerámicos y numismáticos recuperados en los niveles respectivos ${ }^{45}$.

Estas cuestiones nos llevan a plantear un problema doble. El primero de ellos ya ha sido mencionado: dónde habitarían los nuevos pobladores durante todo este prolongado proceso. En este caso, a partir de la evidencia arqueológica disponible para el entorno inmediato de la colonia, especialmente en lo que se refiere a los repertorios cerámicos y numismáticos, podría proponerse que se instalarían en los alrededores de la misma ${ }^{46}$, en estructuras de carácter

40. Como el sólido muro pantalla con contrafuertes que se construyó alrededor del templo sobre podio de la plaza de España. S. García-Dils, S. Ordóñez, O. Rodríguez, "Nuevo templo augusteo en la colonia Augusta Firma Astigi (Écija - Sevilla)", Romula, 6, 2007, 75-114, cit. 85.

41. La red viaria se trazó siguiendo un esquema de retícula ortogonal de kardines y decumani, basada en un módulo básico de 100 pies. S. García-Dils, "El urbanismo de colonia Augusta Firma Astigi (Écija Sevilla). Muralla, viario y red de saneamiento", Romula, 9, 2010, 93-113.

42. S. García-Dils, "Astigi", en J.-A. Remolà, J. Acero (eds.), La gestión de los residuos urbanos en Hispania, Anejos de AEspA vol. LX, Mérida, 2011, 53-63.

43. García-Dils, loc. cit. 2010, 87-92.

44. Se ha caracterizado como temenos el recinto situado en el extremo septentrional del foro colonial, configurado en torno a un templo sobre podio de cronología augustea, García-Dils, op. cit. 2015, 169-242.

45. El arrasamiento sistemático del promontorio donde se ubicaba la Astigi indígena, hasta niveles de los siglos VI-V a.C., se tradujo en que los materiales constructivos y niveles deposicionales correspondientes a los siglos previos a la fundación de la colonia se encuentran desplazados e integrados en estos rellenos masivos, lo que a menudo fue interpretado anteriormente como «materiales rodados».

46. Se trataría de yacimientos como, por ejemplo, el Puente de hierro [41.039.1199] o Villa Paloma [41.039.1234], que más adelante se convertirán en sendas uillae. Por otro lado, mientras se escriben estas 
perecedero de las zonas periurbanas que apenas dejan rastro, además de, probablemente, en el área sureste de la pertica, donde se han registrado las áreas centuriadas. En segundo lugar, y al margen de la posibilidad - no reflejada epigráficamente- de que se integrara entre las élites coloniales a elementos de las aristocracias nativas ${ }^{47}$, no se puede soslayar una cuestión adicional, dónde viven los antiguos pobladores de Astigi Vetus mientras se acondiciona el asentamiento. Tratándose de una ciuitas libera, no parece que se tratara de poena belli, por lo que sería necesario compensar a la población local de alguna manera. En este sentido, se pudo haber planteado algún tipo de fórmula de integración, aunque fuera en una situación jurídica de inferioridad, como corresponde a los incolae ${ }^{48}$. También es factible que se planteara ofrecer una indemnización económica ${ }^{49}$, tal como se refleja en los textos de los agrimensores - en los procesos de centuriación para el mantenimiento de tierras para antiguos habitantes $-{ }^{50}$ o en la epigrafía — caso de los tricastini de Orange-, o quizá, incluso, se llevara a cabo la redistribución de esta población entre el resto de los núcleos indígenas que quedaron incluidos en el seno de la pertica colonial.

\section{El territorio augusteo y julioclaudio}

Con la deductio de colonia Augusta Firma se verifica una profunda transformación en la estructura territorial de la ciuitas libera preexistente, paralela a la que se documenta en el núcleo urbano con la monumentalización de la ciudad, emprendida ya en época augustea ${ }^{51}$.

líneas, a mediados de 2016, la fase en curso de las excavaciones arqueológicas en la plaza de armas del alcázar ecijano, recinto que comprende las cotas más altas del mencionado promontorio donde se ubicaba el oppidum turdetano, están revelando la existencia de infraestructuras de aterrazamiento y estructuras domésticas romanas de época fundacional. Esta circunstancia apunta a que, intramuros de la colonia, probablemente habría un poblamiento inicial de colonos que se iría configurando a medida que se concretaban los trabajos de replanteo y edificación. En este sentido, cabe mencionar que la planta de una de las domus excavadas, cuyos orígenes se sitúan precisamente en estos momentos iniciales de transición, es la única de las registradas en la ciudad cuya orientación se aparta tanto del patrón ortogonal de la colonia, como del previo de época turdetana.

47. Vid. A. Padilla Monge, "La integración de las oligarquías indígenas en las élites coloniales del Sur de Hispania”, en A. Caballos Rufino, S. Demougin (eds.), Migrare. La formation des Elites dans l' Hispanie romaine, Bordeaux, 2006, 205-240, cit. 219-221.

48. P. Sáez, "Notas sobre la pervivencia del elemento indígena en la Bética romana: cuestiones a debate", en La sociedad de la Bética. Contribuciones para su estudio, Granada, 1994, 461-493. A. D. Rizakis, "Incolaeparoikoi: Populations et communautés dépendantes dans les cités et les colonies romaines de l' Orient”, REA 100, 1998, 599-617; Saquete loc. cit. 2010, 85-89.

49. Probablemente se emplearía el expediente de compras para la expropiación, como se ve en $R G$ 16: 260 millones de sestercios en tierras en provincias.

50. Efectivamente, son bien conocidas las menciones a fundi redditi, en zonas no afectadas por centuriación, y fundi commutati pro suo, donde hubiera centuriación.

51. Las reflexiones que siguen se basan en el análisis de la información arqueológica disponible para el territorio histórico de la colonia; vid. supra n. 9. 
Monográfico | Colonia Augusta Firma. Consideraciones sobre su papel económico y político en su contexto fundacional

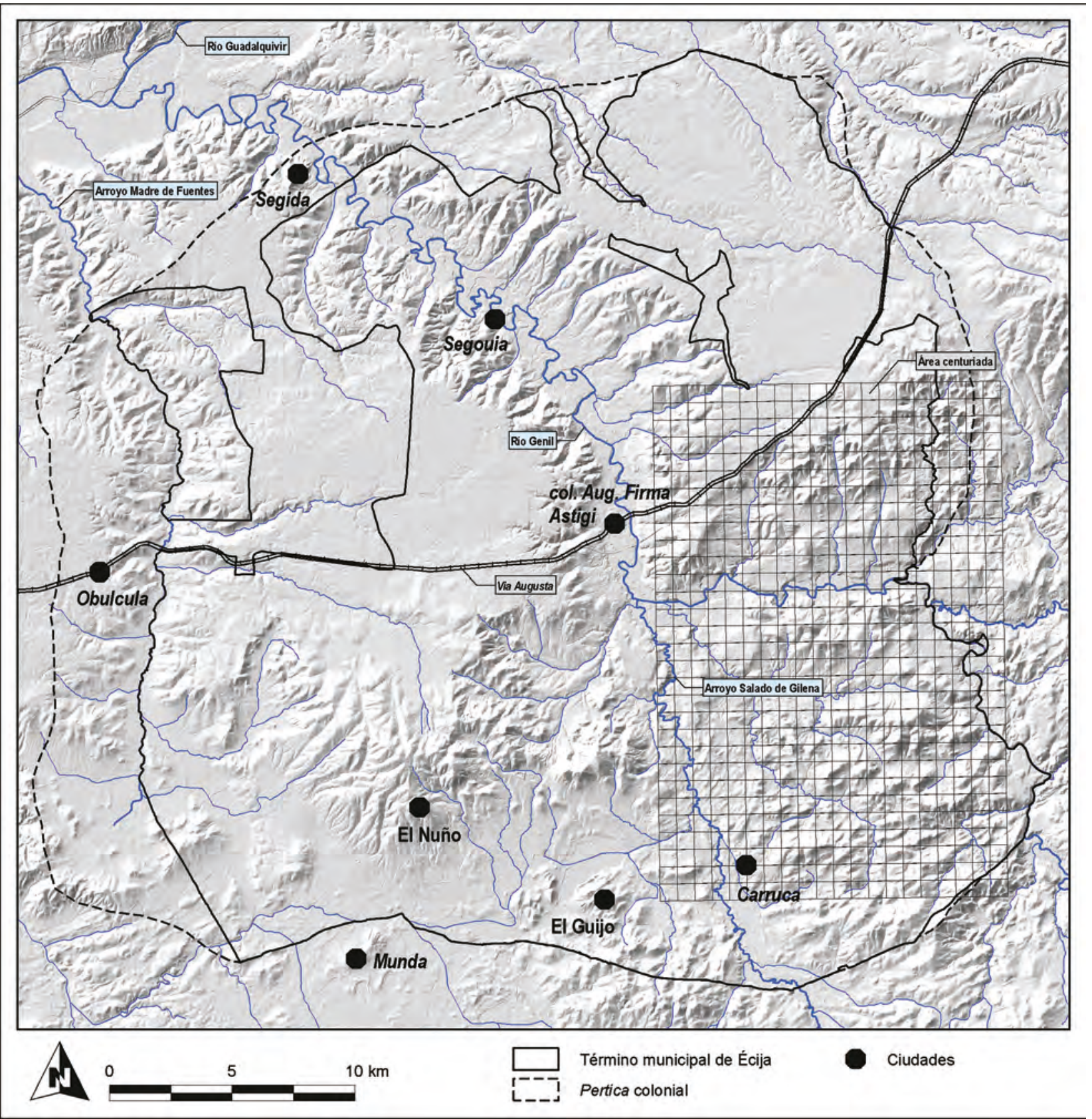

Fig. 2. La pertica de colonia Augusta Firma. 
En principio debió procederse a la creación del territorio asignado a la colonia, al establecimiento de la pertica colonial y la delimitación de sus fines. La extensión de esta demarcación se ha inferido de la combinación del recurso a los epígrafes con la mención de la tribu Papiria hallados a relativa distancia de Écija - todos ellos en su sector meridional, en un radio entre 20-30 km de la ciudad ${ }^{52}$ - con la información proporcionada por el texto del Repartimiento del año 1263, cuyos hitos pueden georeferenciarse con bastante certidumbre. Este documento nos transmite los límites territoriales asignados al iqlim de la madina en época andalusí, que se mantuvieron como tales en la fase cristiana. Consideramos metodológicamente útil la proyección a época romana de los límites del siglo XIII, con las lógicas salvedades de la evolución puntual y modificaciones de detalle que el territorio debió experimentar a lo largo de una fase tan dilatada de tiempo. Dicha proyección se encuentra en cierta medida avalada por el hecho de que desde el siglo XIII hasta la actualidad el término municipal de Écija no ha experimentado alteraciones sustanciales con la excepción de la segregación que se operó en época de Carlos III con la fundación de las colonias de La Luisiana y La Carlota y las pequeñas amputaciones que arrebataron ciertas extensiones de terreno, hoy día bajo la jurisdicción de los términos municipales limítrofes. Con ello se obtiene una extensión territorial muy amplia, en torno a $1200 \mathrm{~km}^{2}$, que posiblemente fuera en tiempos antiguos incluso mayor. Con ello se creaban los cimientos de su rica economía agraria [Fig. 2].

A partir del establecimiento del territorio se procedió a la centuriación de una zona del mismo y a la imposición del modelo romano de reorganización territorial con base en la formula censualis. Por ello, se observa una realidad compleja en la que coexisten pagi $i^{53}$, pequeñas aglomeraciones, uillae con sus fundi, incluso la continuidad de oppida indígenas en el interior del territorio colonial. La trama centurial, localizada mediante tecnología SIG ${ }^{54}$, ocupa solo una fracción del territorio asignado, unos $170 \mathrm{~km}^{2}$, extendiéndose sobre unas tierras de excelentes y buenas potencialidades agrícolas. Con una orientación $359^{\circ} \mathrm{NO}$, por tanto sin continuidad con el viario urbano, la red centurial se estableció bajo un módulo de 20 por 20 actus, equivalente a $710 \mathrm{~m}$. En lo que se refiere a la datación de esta centuriación, la fundación de colonia Augusta Firma a fines del siglo I a.C. permite establecer un terminus post

52. CIL II²/5, 995, 1247, 1284; CIL II 1396, 1398. A ellos se añade una pieza aparecida en el extremo NE de la pertica, en el entorno de La Carlota, de cronología de inicios del Imperio; vid. S. Ordóñez, S. GarcíaDils, J. Moralejo, "Nuevas inscripciones de militares de colonia Augusta Firma y la delimitación de la pertica colonial en su sector nororiental", en A Baete ad fluvium Anam. Cultura epigráfica en la Bética occidental y territorios fronterizos, Madrid, 2016, 99-122.

53. Por el momento, se tiene constancia de dos pagi en la pertica astigitana, el pagus Singiliensis, mencionado en CIL II ${ }^{2} / 5,989$ y, recientemente, el pagus Venerius -con mención de un magister pagi y un paganicum porticado- documentado a partir de una inscripción de época augustea localizada en la Camorra de las Cabezuelas; A. Ventura, A. U. Stylow, "El pagus Venerius (pertica Astigitana) y su paganicum. Nuevos datos sobre la organización del territorio de la colonia Augusta Firma en una inscripción de 'La Camorra de las Cabezuelas'”, Antiquitas 27, 2015, 85-94. Ambos pagi se sitúan en el cuadrante suroriental del territorio colonial.

54. P. Sáez, S. Ordóñez, S. García-Dils, "Le territoire d’Astigi (Écija). La centuriation”, en Atlas historique des cadastres d' Europe, Luxembourg, 2002, dossier 2, 1-14. 
quem, coincidente además con la información arqueológica que proporciona la prospección sobre el terreno, según la cual es a partir de época de Augusto cuando el sistema prerromano de implantación en el territorio se ve progresivamente sustituido por un esquema diferente bajo el dominio de la propiedad rural dispersa - uillae - inserta en la nueva estructura de pagi y uici, con la consiguiente modificación de las condiciones de ocupación del suelo.

El territorio asignado, en el que la homogeneidad de relieves suaves y pendientes poco pronunciadas y donde las formaciones más representativas son las pedillanuras y los cerros alomados, contaba con unas excelentes condiciones edafológicas y con una gran capacidad de aprovechamiento agrícola. En él se situaban salinas ${ }^{55}$, canteras, masas boscosas espesas - saltus - , dehesas, pastos y baldíos, lagunas y humedales endorreicos, espacios todos ellos que constituían activos económicos complementarios a las explotaciones agrícolas - viticultura, uillaticae pastiones, piscicultura, pastos, caza- y que configuraron desde los inicios un paisaje agrario sumamente complejo que garantizaba unas bases económicas que no se sustentaban exclusivamente en los cultivos de alto rendimiento. En conjunto, en el territorio astigitano estamos en presencia de tierras muy buenas para la práctica agrícola, a excepción de pequeños islotes, que indican un gran potencial a la hora de la explotación de las mismas. De hecho, todo el territorio colonial se halla en su conjunto incluido en el rango de aquellas tierras con suelos y tierras de excelente y buena capacidad de uso, conformados por fluvisoles calcáreos, vertisoles y cambisoles, con ciertos ámbitos -tierras de arcillas expansivas, encharcables y difícilmente explotables desde el punto de vista estrictamente agrario, y zonas endorreicas y baldíos- donde las dificultades de la tecnología impedían el aprovechamiento para cultivos pero no su uso alternativo como pastizales, forrajeo o caza ${ }^{56}$.

El estudio del territorio astigitano ha puesto de relieve que a partir de los primeros decenios del siglo I d.C. se produjo una importante eclosión del poblamiento rural. Si en época prerromana predomina un poblamiento concentrado en un reducido número de comunidades, las ciuitates / oppida, donde reside un campesinado que trabaja los predios rurales más inmediatos al núcleo habitado, que proporciona seguridad, quedando el campo abierto prácticamente deshabitado, el impacto de la colonización augustea, con la difusión de uici, uillae dispersas y pequeños asentamientos, cambiará drásticamente este modelo de poblamiento. En claro contraste con la situación anterior, el territorio se puebla intensivamente, lo que se plasma en el incremento decidido de explotaciones — uillae y pequeños hábitats rurales-, donde es la fundación colonial la que actúa como revulsivo, aunque no desde el momento de la deductio sino en época algo posterior, a partir de los reinados de Claudio y Nerón, a tenor de los elementos fechables documentados sobre el terreno. En este sentido, resulta de gran interés vincular este fenómeno con las medidas que el Estado, como principal motor de la eco-

55. S. García-Dils, P. Orche, P. Sáez, S. Ordóñez, "Estudio diacrónico de la explotación de la sal en el territorio histórico de Écija (Sevilla)", en Actas del I Congreso Internacional «La explotación histórica de la sal: investigación y puesta en valor», Ciempozuelos, 2009, 73-90.

56. Todavía en el siglo XV la documentación refiere la caza de gamos, ciervos, jabalíes, lobos y osos; vid. M. Martín, Ordenanzas del concejo de Écija (1465-1600), Écija, 1990, 75; D. P. Seniff (Ed.), Libro de la Montería de Alfonso XI, based on Escorial MS Y.II.19, Madison, 1983, 119, 124. 
nomía imperial, emprende para favorecer la producción y alentar los mercados en su política de atender las necesidades de abastecimiento, en este caso específico, de aceite. Como es bien sabido, el cultivo del olivo experimenta un crecimiento muy importante a partir de la fundación colonial, aprovechando las ventajas edafológicas del terreno, la calidad del producto y las posibilidades de exportarlo de forma eficiente y barata a lejanos mercados de consumo. Este cultivo dio una impronta particular al paisaje astigitano, convirtiéndose en la clave de la potencia económica y social de la colonia y en la prosperidad de sus élites dirigentes.

En el ámbito territorial quizá el mejor testimonio de esta dinámica sea el doble modelo de expansión del olivo en el territorio ecijano, que fue conformándose como resultado de la colonización. Los estudios desarrollados en los últimos años ${ }^{57}$ permiten formular una hipótesis de plasmación cartográfica del paisaje agrario astigitano que toma como base los restos arqueológicos, así como la comparación y el prudente contraste con la información proporcionada por la documentación de tiempos medievales y modernos. De ella se desprende que en época romana el olivo pudo estar plantado en casi todos los lugares del territorio astigitano, generando un paisaje próximo a lo que se podrían denominar dehesas de olivar, aunque extendiéndose predominantemente sobre los cuadrantes nororiental y suroccidental del territorio ciudadano, tomando como ejes de esta disposición la uia Augusta así como la ruta que se dirigía al Estrecho de Gibraltar. En épocas bajomedieval cristiana y moderna, estas áreas se denominaban, respectivamente, Banda Morisca (NE) y Valcargado (SO), donde se practicarían marcos de olivos reducidos, con una mayor intensificación del cultivo. Complementariamente, el olivo se extendía por el resto del territorio, de forma extensiva y en marcos muy grandes, no como cultivo preferente sino secundario respecto a cereales y aprovechamientos ganaderos, lo que generaba una forma supletoria de renta de la tierra, o al menos de una renta de pocos gastos. La gran producción de aceite que sugieren los hallazgos de ánforas con registro de control de Astigi estaría así basada más en la práctica extensiva del cultivo del olivo que en la intensificación del mismo.

El modelo se completaba con la implantación de instalaciones industriales a orillas del río con cronología y adscripción espacial muy precisas. La explosión de la producción alfarera en el entorno astigitano se produce con posterioridad al reinado de Augusto, cuando la puesta en valor del territorio colonial empieza a dar sus frutos. Para entonces se encuentran operativas las alfarerías de Las Delicias y Alcotrista, la primera exportando su aceite ya en los años 30 d.C. en ánforas selladas ${ }^{58}$. Con ellas se da inicio al nacimiento de lo que en el futuro inmediato, y durante 200 años, será un verdadero polo industrial a lo largo de $20 \mathrm{~km}$,

57. Vid. supra n. 9.

58. S. Martin-Kilcher, "Les amphores romaines à huile de la Bétique (Dressel 20 et 23) d'Augst (Colonia Augusta Rauricorum). Un rapport préliminaire”, en II Congreso internacional sobre el aceite en la Antigüedad, Madrid, 1983, 337-347, cit. 346; G. Chic, E. García, "Alfares y producciones cerámicas en la Provincia de Sevilla. Balance y perspectivas", en Figlinae Baeticae. Talleres alfareros y producciones cerámicas en la Bética romana (ss. II a.C.-VII d.C.), Oxford, 2004, 279-347, cit. 293; P. Berni, Epigrafía anfórica de la Bética. Nuevas formas de análisis, Barcelona 2008, 426 ss.; S. Mauné et al., "L'atelier d'amphores à huile Dr. 20 de Las Delicias à Ecija (Prov. de Séville, Espagne). Résultats de la campagne de fouille 2013 et perspectives", en Actes du Congrès International de la SFECAG, Marseille, 2014, 365-388. 
generando una compleja dinámica de producción intensiva que articula redes de aprovisionamiento de materia prima, combustible, infraestructura de producción, almacenamiento y transformación, creación de rutas comerciales estables, generación de mercados, etc. Por el momento, estos alfares dan muestras de la implantación de un complejo sistema de gestión, en el que éstos son concebidos como anexos a la explotación agrícola, a través de mecanismos de arrendamiento de parte o de toda la infraestructura productiva de las figlinae al margen de la gestión directa del propietario. Parece evidente que el proceso de germinación de una actividad alfarera de carácter industrial trabajando hacia el exterior y gestionada de forma independiente de la explotación agrícola - que tomará cuerpo a mediados del siglo II d.C.-, se ha de situar 100 años antes, y que se encuentra ilustrado por las marcas de estos alfares, que apuntan a la emergencia de una «clase profesional» de alfareros que irá asentándose progresivamente ${ }^{59}$. Con todo, será ya en el siglo II d.C. cuando tengan lugar una serie de transformaciones fundamentales en el ámbito de la producción y exportación olearias, que cambiarán radicalmente el paisaje agrario a orillas del río y las formas de propiedad y gestión de las alfarerías, impulsadas por el incremento exponencial de las necesidades de abastecimiento oleario, tanto de los particulares como, especialmente, del Estado.

La trama centurial detectada cubre en torno a un $17-18 \%$ del territorio comprendido dentro de la pertica colonial. Ello refleja que una gran parte de la tierra no fue centuriada $\mathrm{y}$, por tanto, asignada - ager diuisus et assignatus - $\mathrm{y}$, aunque pudo pasar a alguna de las diversas situaciones que se contemplan en los escritos de los agrimensores-siluae et pascua publica coloniae, siluae et pascua publica colonorum, compascua, subseciua, agri uectigales, etc.-, también es muy factible que el resto quedasen en manos de las comunidades peregrinas preexistentes -Carruca, Obulcula, Segouia, Segida, y otras de nombre antiguo no conocido-. En cualquier caso, y aunque no se pueda establecer el sistema concreto, todo parece indicar que esas comunidades indígenas debieron disponer de un status de alguna forma privilegiado en el proceso fundacional. En este sentido, estas ciuitates continuaron manteniendo su territorio y sus formas organizativas propias hasta su conversión en municipios flavios, aunque dependiendo del centro colonial, sin que este cambio estatutario afectara a la integridad territorial de la pertica ni a la dependencia fiscal de estas comunidades para con la colonia, que seguiría manteniendo los ingresos que había obtenido hasta el cambio estatutario $^{60}$. Con el tiempo, en el siglo II d.C., la atracción que suponía la colonia como centro de poder y representación terminaría descapitalizando a los nuevos municipios, proceso que explica la confluencia de fenómenos tan llamativos, y opuestos, como la coincidencia temporal de la culminación de la monumentalización del centro colonial y la lánguida realidad arqueológica y edilicia de estas entidades municipales.

El territorio de una colonia puede ser discontinuo y fragmentado, como conocemos que ocurría en Arausio, Carthago, Philippi o Augusta Emerita. Para el caso astigitano dispo-

59. E. García, "La producción de ánforas romanas en el sur de Hispania. República y Alto Imperio”, en Ex Baetica amphorae. Conservas, aceite y vino de la Bética en el Imperio Romano. Vol. I, Écija, 2001, 57-174, cit. 118,120 .

60. Sobre estos procesos, Sáez, Ordóñez, García-Dils, loc. cit. 2008. 


\section{(COLON AVGVSTIFIRMVIIIIAFERM) :}

Fig. 3. Lingote de plomo de Cartagena (A. Beltrán).

nemos de un testimonio que certifica la atribución de una praefectura. Estas tierras de condición extraterritorial podían ser tanto de labor como pastos. Pero también podían incluir explotaciones mineras, sin duda uno de los grandes activos de los que podía beneficiarse una comunidad urbana. Un lingote de plomo encontrado en Cartagena ${ }^{61}$, actualmente en paradero desconocido, con la inscripción COLON(orum) AVGVSTIFIRM(orum)/FERM ${ }^{62}$ [Fig. 3], conduce a pensar precisamente en la existencia de una praefectura adscrita al territorio de la colonia astigitana, en cuyo interior se situaría una mina que formaría parte de los uectigalia de la ciudad ${ }^{63}$. Este lingote puede fecharse en el siglo I d.C. o, en todo caso, en fecha posterior a la deductio colonial. No podemos saber con seguridad la ubicación del coto minero, que pudo estar en Sierra Morena o, mejor, en alguna de las zonas metalíferas de la Alta Andalucía con acceso directo al puerto de Carthago Noua. La existencia de esta pieza certifica que los ingresos de esta ciudad eran diversos y que no se limitaban al aprovechamiento de las posibilidades que proporcionaba su ya de por sí rica economía agraria ${ }^{64}$.

61. A. Beltrán, "Objetos romanos de plomo en el Museo de Cartagena y sus inscripciones", MMAP, 8, 1947, 202-209, cit. 204 n 1; C. Domergue, Les mines de la péninsule Ibérique dans l’ Antiquité romaine, Roma $1990,236$.

62. El dibujo original de la pieza, único testimonio que se conserva, permite la reconstrucción en genitivo plural, más adecuado que el nominativo plural.

63. P. Sáez, "Algunas consideraciones sobre el territorio de las ciudades de la Bética", en Estudios sobre las ciudades de la Bética, Granada 2002, 389-445, cit. 426-429; Sáez, Ordóñez, García-Dils, loc. cit., 2007, 160; A. Orejas, C. Rico, "Metalla, civitates, coloniae: les mines hispaniques dans les processus de changement des statuts territoriaux à la fin de la République et au début de l' Empire”, en A. Bertrand (Ed.), Expropriations et confiscations en Italie et dans les provinces: la colonisation sous la République et l'Empire, MEFRA 127.2, 2015 (on line).

64. Cabe preguntarse a este respecto si en IRPC 513 no podríamos estar ante otra situación de extraterritorialidad, en este caso quizá vinculada con tierras de dedicación ganadera o de explotación de saltus inmediatas a la sierra gaditana. 


\section{Resultados. La ciudad toma impulso}

Los resultados del impulso inicial que recibe la ciudad y su territorio desde la fundación no tardarán en verse. La boyante economía de la ciudad se aprecia especialmente en las evidencias de la arqueología urbana, con la primera monumentalización de la ciudad, ya apreciable desde la misma época augustea, pero sobre todo en época flavia ${ }^{65}$. En la segunda mitad del siglo I d.C. se verifica el mantenimiento de la línea urbanística emprendida en el período anterior. Con todo, quizá, más que de «impulso monumentalizador», habría que hablar de la consolidación de la política de infraestructuras realizada a lo largo del período fundacional, tratándose más bien de la culminación de un proceso, en el que, sobre las bases previas, se empiezan a levantar nuevos edificios, pavimentándose con losas pétreas las amplias áreas forenses, que hasta entonces no eran más que una gran explanada aterrada, y las calles, utilizándose como sub-base el firme de tierra que presentaban inicialmente. Ello daría sentido al hecho de que en algunos casos los pavimentos de las vías están, en cota, por encima de los niveles de suelo domésticos de época fundacional, como vemos en las viviendas anejas a los kardines excavados en la plaza de España. En este proceso se prestó especial atención a la evacuación de aguas pluviales y residuales, cuestión capital en una ciudad situada en el fondo de una depresión a orillas de un río con ocasionales episodios de avenidas de aguas. Se trata de cloacae de gran entidad, construidas con bloques de calcarenita. Salvo en el caso particular del foro colonial y su canal perimetral, todo el saneamiento está vinculado al viario, discurriendo la práctica totalidad de las cloacas documentadas bajo los ejes centrales de algunas de las vías, ya sean kardines o decumani. La mayoría están vinculadas a decumani, conduciendo los vertidos hacia el este de la ciudad, en dirección al río Genil. Resulta interesante constatar que las infraestructuras que no se construyan en el primer siglo de existencia de la ciudad, ya no se realizarán más adelante, y ello a pesar de evidentes problemas de estabilidad de edificios y del pavimento de las calzadas, que se colapsan en diferentes puntos. Sea porque no se diagnostica correctamente el problema, o por falta de medios o interés por parte de las autoridades ciudadanas, no se llega a construir las cloacae en los lugares necesarios, sino que, por el contrario, se recurre a actuaciones parciales, como rellenar los huecos en las calzadas o recalzar puntualmente pilares o muros de las edificaciones cercanas.

En el temenos se realizaron importantes reformas, construyéndose el imponente muro de opus quadratum del peribolos, con un acceso porticado situado en su puerta noroeste, así como la cloaca situada bajo el decumanus 8 , para garantizar la evacuación de aguas del recinto religioso. También ha de situarse en esta fase de mediados del siglo I d.C., a partir de los datos aportados por las diferentes excavaciones, la construcción de las infraestructuras que cabe asociar con el circo colonial.

A juzgar por la evidencia anfórica, es a partir de época flavia cuando se alcanzarán los niveles más altos de exportación, y más aún a partir de Adriano, momento en el que las entregas a la Annona se harán obligatorias. Ello coincide con el máximo esplendor urbano que

65. Sobre la configuración del urbanismo de la colonia y su evolución desde época fundacional, vid. García-Dils, op. cit. 2015. 
reflejan los registros arqueológico y epigráfico, que muestran que la riqueza y el nivel de desarrollo de la colonia durante el siglo II d.C. dependen sustancialmente de la implicación en los negocios de la comercialización del aceite. La presencia de marcas de ánfora fabricadas en las alfarerías astigitanas se incrementa de forma decidida en diferentes puntos del Imperio, en demostración de la operatividad de las redes comerciales que encaminan el aceite producido en el ager Astigitanus a los mercados de consumo a través de rutas estables y con mucho tráfico. Este tráfico, y lo que ello implica, han sido explorados con importantes y novedosos resultados por la investigación en los últimos decenios ${ }^{66}$. Por ello, preferimos ahora ceñirnos a un ámbito menos cursado de los estudios antiguos, y que resulta clave, en nuestra opinión, a la hora de definir los parámetros con los que se ha de definir lo que son las «ciudades del poder», su magnitud poblacional, su importancia demográfica ${ }^{67}$.

Frente a planteamientos tradicionales del tipo «¿cuánta gente cabe en el anfiteatro?» ${ }^{68}$, nuestro acercamiento se basa en la idea de intentar calibrar, reconociendo todas las limitaciones de la propuesta, qué potencial humano se necesitaría para que todo el sistema fuese operativo, esto es, la población de la ciudad, pero también la del territorio. La aplicación de los parámetros propuestos por la investigación sobre demografía en Hispania ${ }^{69}$ a los datos actualizados disponibles en el agro y núcleo astigitanos lleva a una cifra de conjunto de 35.000 habitantes, mientras que una reciente estimación ${ }^{70}$ sugiere una población para la ciudad en un rango entre $c a .10 .000$ y $c a .16 .000$, y de entre $c a .30 .000$ y $c a .47 .000$ para el territorio. Ambas magnitudes parecen excesivas.

No es este el lugar para desarrollar al completo toda la argumentación al respecto ${ }^{71}$, por lo que se realizará aquí sólo una síntesis de la misma. La idea parte de los datos proporcionados por los agrónomos latinos, particularmente Columela, un natural del país, sobre las necesidades de mano de obra para atender la explotación de un terreno, en combinación con las dimensiones territoriales y poblacionales de la Écija de época moderna -reflejadas particularmente en el Catastro de Ensenada-, en la idea de que no debió haber muchas diferencias en técnicas de cultivo y conocimientos operativos entre época romana y el siglo XVIII, siendo ambas sociedades preindustriales y, por tanto, eminentemente campesinas. En

66. Son bien conocidos al respecto los trabajos de J. Remesal, G. Chic, C. Carreras o P. Berni, entre otros. 67. Uno de rasgos característicos de la mentalidad romana es considerar una población abundante como una de las mayores bendiciones de las que podía disfrutar una ciudad o una región, vid. P. Horden, N. Purcell, The corrupting Sea, Oxford 2000, 377 ss.; W. Scheidel, "Population and demography", accesible en http://www.princeton.edu/ pswpc/papers/authorMZ/scheidel/scheidel.html: In pre-modern societies, population size was the best indicator of economic performance (p. 2).

68. El aforo del anfiteatro astigitano ha sido calculado, a partir de su comparación con el de Itálica, entre 12.500 y 22.000 plazas, vid. I. Carrasco, A. Jiménez, “Acerca de los edificios de espectáculos en Colonia Augusta Firma Astigi (Écija, Sevilla)", Romula, 7, 2008, 7-52.

69. C. Carreras, "Una nueva perspectiva para el estudio demográfico de la Hispania romana”, BSAA, 62, 1996, 95-122.

70. S. J. Keay, G. Earl, “Towns and Territories in Roman Baetica”, en A. Bowman, A. Wilson (eds.), Settlement, Urbanization, and Population, Oxford, 2011, 276-316, cit. 305.

71. Expuesta, de nuevo en el documento inédito citado supra en n. 9. 


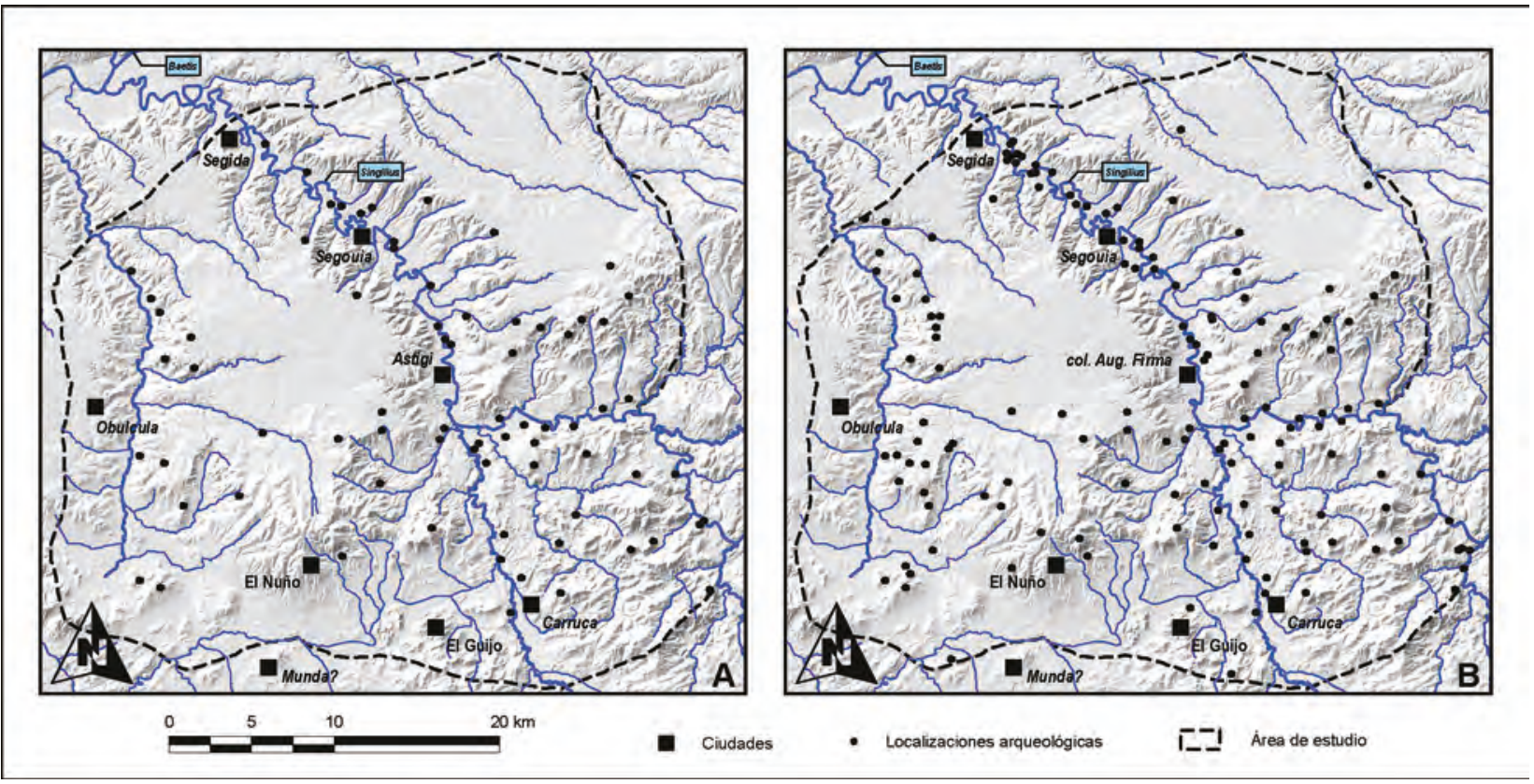

Fig. 4. Ocupación del territorio en época Republicana y Altoimperial.

este acercamiento se consideran diferentes variables que afectan tanto a la población urbana, como, sobre todo, a la que poblaba el ager en sus diferentes condiciones - tierras cultivables, montes, baldíos y dehesas-, así como los núcleos urbanos incluidos en la pertica.

Obviamente, debió haber diferencias importantes entre la época de la fundación y las fases álgidas del desarrollo de la ciudad, en el siglo II y III d.C. [Fig. 4].

Para el momento fundacional ya se ha señalado que la media de colonos establecidos en las colonias augusteas fundadas en torno al último cuarto del s. I a.C. puede establecerse entre 2000 y $3000^{72}$, cifra que se eleva algo en otros cálculos, que apuntan, para las colonias itálicas, a una media entre 3000 y 4000 colonos $^{73}$. Las valoraciones sobre los efectivos demográficos de otros centros urbanos descansan también sobre bases muy frágiles y altamente especulativas. No obstante, y apoyándonos en las estimaciones realizadas por Morley, DuncanJones y Lo Cascio, y en la jerarquía urbana que se deriva de ellas, se puede aceptar que la gran mayoría de las ciudades, al menos en Italia, eran centros de pequeña entidad, con una pobla-

72. De las pocas cifras concretas de que se dispone destaca la de Augusta Praetoria, colonia augustea, deducida con 3000 colonos (Str. 4.6.7).

73. O bien es reducida drásticamente. J. C. Mann, Legionary recruitment and veteran settlement during the Principate, London 1983, 59, calcula una media en torno a 1000 colonos. 
ción de unos pocos miles de habitantes, en cualquier caso sin sobrepasar los 5000 libres $^{74}$. Los grandes puertos, Ostia y Puteoli, alcanzarían hasta 30.000 habitantes, una media a la que llegarían también algunos centros de carácter regional como Capua, Patauium o Mediolanum. En fin, un grupo de 25 ciudades, muchas de ellas de raíces coloniales, se situarían en el rango entre 5000 y 25.000, con una media de 15.000 habitantes. Ahí se incluyen ciudades como Placentia, Cremona, Parma, Mutina, Bononia, Comum, Dertona, Beneuentum, Canusium, Verona, Corfinium, Spoletium, Pisaurum, entre otras. Parece muy factible considerar la realidad poblacional del caso astigitano a la luz de este último grupo de ciudades, con alguna de las cuales, como Bononia, con sus 50 ha, ofrece similitudes en cuanto a las dimensiones de sus recintos urbanos y al papel que desempeñan en relación con su hinterland.

A la vista de todas las consideraciones previas, y adoptando un punto de vista cercano a la posición de los low-counters, que nos parece más ajustado visto el escaso desarrollo de la demografía en el mundo antiguo, creemos que se podría establecer, en una estimación razonable, que la población total de colonia Augusta Firma pudo haber alcanzado una cifra en torno a los 20.000 habitantes $^{75}$. Ello significaría que la densidad de población en el ager Astigitanus se situaría, sobre la base del término municipal histórico sobre el que trabajamos, en $16,2 \mathrm{hab} / \mathrm{km}^{2}$, cifra plenamente coincidente, en líneas generales, con la que se ha propuesto recientemente para la Península Ibérica (12-15 hab $/ \mathrm{km}^{2}$, con una estimación de 7-9 millones de habitantes) y la del Imperio en su conjunto (16-19 hab $/ \mathrm{km}^{2}$ para una población total estimada entre 59-72 millones) ${ }^{76}$.

La dimensión poblacional estimada justifica sobradamente la consideración de metrópolis que Astigi merecía a ojos de algunos escritores grecorromanos, como Estrabón (Str. 3.2.2), que la sitúa entre las poblaciones más importantes de la Turdetania, o Mela (2.88), quien menciona a mediados del siglo I d.C. a Hastigi en primer lugar en el listado de las tres poblaciones más relevantes -clarissimae- de la Baetica junto con Hispal, la capital económica, y Corduba, la capital política provincial.

74. R. Duncan-Jones, The Economy of the Roman Empire. Quantitative Studies, Cambridge, 1974, 259 ss.; N. Morley, Metropolis and Hinterland. The city of Rome and the Italian economy. 200 B.C.-A.D. 200, New York 1996, 182; E. Lo Cascio, “The Population of Roman Italy in Town and Country”, en J. Bintliff, K. Sbonias (Eds.), Reconstructing Past Population Trends in Mediterranean Europe (3000 BC - AD 1800), Oxford, 1999, 161-171. Las estimaciones se refieren fundamentalmente a mediados del siglo I d.C.

75. Sin que sea posible tener en cuenta el factor de la evolución temporal en esta estimación. Evidentemente la fundación de la colonia supondría un punto de inflexión en la realidad demográfica imperante hasta el momento, dado que la urbanización representa siempre un incremento de la tasa poblacional, incluyendo los sectores no agrarios. Para los siglos XII-XIII se ha estimado la población residente intramuros del núcleo amurallado en unas 14.000 personas, corrigiendo a la baja cálculos anteriores de Gerbert y Torres Balbás, que apuntaban a 18.000 habitantes; A. Fernández, "Écija en la economía de al-Andalus: algunos indicadores cuantitativos de su importancia”, en VII Congreso de Historia de Écija. Economía y sociedad, Écija, 2005, 215-238, cit. 223. No se dispone de estimaciones sobre la población rural; las deficiencias en el registro arqueológico de época andalusí impiden por el momento cualquier elucubración al respecto.

76. W. Scheidel, “Demography”, en W. Scheidel, I. Morris, R. Saller (eds.), The Cambridge economic history of the Greco-Roman world, Cambridge, 2007, 48, table 3.1. 
Con todo, confrontando la cifra de 20.000 habitantes con la situación que se conoce en la misma ciudad en el siglo XVII, con ocupaciones del 60\% en la agricultura, se obtiene una mano de obra agrícola cercana a 8000 operarios. Con ese número de trabajadores sólo se podría poner en cultivo o explotación, según las estimaciones manejadas, un porcentaje en torno al 47\% de la superficie total del ager Astigitanus. De ello se infiere que el paisaje de la antigua Écija que se nos dibuja a partir de estas cifras con trazos ciertamente gruesos, resulta ser un paisaje muy poco antropizado, donde serían predominantes los espacios incultos, los baldíos, el monte y las dehesas, que ocuparían más de la mitad del territorio considerado, ofreciendo de este modo una perspectiva muy diferente, menos simplista y más compleja, con la que valorar las posibilidades y el alcance de explotación de un territorio. Como en tantos otros casos, conviene de nuevo relativizar las visiones presentistas de las realidades antiguas.

\section{Epílogo}

¿Hasta qué punto fue colonia Augusta Firma una «ciudad del poder»? En principio su condición de colonia, como establecimiento patrocinado por el poder imperial, que controla todos los resortes del proceso fundacional, favorecía de partida una posición privilegiada frente al resto de comunidades del entorno como speculum populi Romani. En las primeras décadas la intervención estatal, que debió de ser de envergadura, en combinación con el esfuerzo de los colonos en prestaciones de trabajo y la inversión de fondos de la comunidad ${ }^{77}$, después no será tan necesaria, al menos en el ámbito concreto de la colonia. Tras los primeros decenios de funcionamiento, la ciudad es grande y rica, pero «camina sola», sin necesidad de una continua intervención imperial. Mención aparte merece, obviamente, su condición de sede para las reuniones de la asamblea conventual, con la presencia periódica del gobernador, como representante del poder imperial y de Roma, para las sesiones judiciales, lo que automáticamente situaba a la colonia por encima de las demás ciuitates y sólo por debajo de la capital provincial en lo referido a la capacidad de atracción de recursos económicos y gentes foráneas. Aparte de esta cuestión, en las fuentes disponibles no se aprecia que la colonia se caracterizara especialmente por ser un espacio de representación de la Casa Imperial ni de las élites dirigentes, al menos al modo de otras ciudades de la provincia, como Italica o Corduba. Más bien, la sensación que se desprende de su evidencia arqueológica y epigráfica es la de un mundo de contactos y riqueza, bien interrelacionado con los núcleos económicos de la provincia y del imperio, con élites que podían poner en marcha procesos de construcción de infraestructuras urbanas de grandes dimensiones y para los cuales podían importar materiales de lujo del Mediterráneo, aprovechando las redes de contacto con el resto del imperio que facilitaba el comercio oleario. Uno de los escasos testimonios de la presencia del poder de que

77. Cf. H. Jouffroy, "Le financement des constructions publiques en Italie. Initiative municipale, initiative impériale, évergétisme privé”, Ktema, 2, 1977, 329-337; H. Jouffroy, La construction publique en Italie et dans l'Afrique romain, Strasbourg, 1986. 
disponemos se deriva precisamente de la relevancia de colonia Augusta Firma en el ámbito económico. En un momento indeterminado del siglo II d.C. la maquinaria administrativa estatal establecerá en el lugar una de las oficinas de control fiscal sobre los productores y la producción olearia, reflejada en la consignación, desde ese momento, del nombre indígena de la ciudad en los tituli picti de las ánforas ${ }^{78}$, y probablemente, en la ubicación de un tabularium o un arca, con sus funcionarios. El intervencionismo estatal en el plano económico generó así una región fiscal para establecer el control de la producción anual con centro en la cabecera de la comarca, lo que hubo de considerarse seguramente como una forma muy efectiva de expresión del poder. De nuevo, como en los momentos de la fundación, razones económicas y accesibilidad a la navegación estaban en la base de una decisión de calado. Teniendo siempre presente la aleatoriedad de la preservación del registro arqueológico y epigráfico, resulta no obstante llamativo el escaso reflejo de las manifestaciones del poder, particularmente las contadas dedicaciones epigráficas a la figura imperial, así como de sus manifestaciones iconográficas. Estas últimas se reducen a un retrato de Vespasiano, siendo el resto de la plástica de carácter ideal ${ }^{79}$, aunque lógicamente hay que pensar en la evidente presencia de otros muchos personajes de la casa imperial en la estatuaria astigitana, representaciones que no han llegado hasta nosotros ${ }^{80}$. Para los primeros momentos de su trayectoria histórica, algunas piezas muestran la acción de los genearcas y la rápida transformación del contingente militar en sociedad civil ${ }^{81}$; por su parte, un patrono de época temprana figura contribuyendo a la ornamentación del templo en sus monumentales lastras, templo que en un momento dado reflejará su monumentalización mediante el recurso de las litterae aureae ${ }^{82}$. Un rasgo llamativo y revelador es la inexistencia, por el momento, de senadores originarios de Écija ${ }^{83}$, algo que se adecua al perfil de esta ciudad como comunidad de reciente creación y volcada al mundo de los negocios y del intercambio, generadora de unas élites mercantiles enriquecidas de las que las inscripciones conservadas son muestra elocuente y que dan un tono social particular a la ciudad en su práctica evergética ${ }^{84}$. También es patente la escasa presencia de gente implicada en la administración imperial. En época de Nerva y Trajano P. Postumius Acilianus

78. G. Chic, Epigrafía anfórica de la Bética. II, Sevilla, 1988, 73.

79. M. J. Merchán, Corpus Signorum Imperii Romani. España. Écija (Provincia de Sevilla. Hispania Vlterior Baetica), Sevilla-Tarragona, 2015.

80. En la línea de lo señalado por J. Arce, "Estatuas y retratos imperiales en Hispania romana", AEspA 75, 2002, 235-250.

81. CIL II'/5, 1168, 1169; AE 2001, $1204=$ HEp 11, 457.

82. S. Ordóñez, S. García-Dils, "Evidencia de inscripciones monumentales asociadas al templo principal de colonia Augusta Firma", Habis, 44, 2013, 157-184.

83. Vid. A. Caballos, "La Romanización de las ciudades de la Bética y el surgimiento de senadores provinciales", Revista de Estudios Andaluces, 6, 1986, 13-26, cit. 24-26. No obstante, existen testimonios de intereses y propiedades senatoriales en las tierras astigitanas a través de la evidencia anfórica; vid. algunos ejemplos en A. Caballos, "Los recursos económicos de los notables de la Bética”, en M. Navarro, S. Demougin (eds.), Élites hispaniques, Burdeos 2001, 69-87.

84. CIL II²/5, 1162, 1164, 1165, 1166, 1171, 1175; S. Ordóñez, J. C. Saquete, S. García-Dils, "Dos nuevos pedestales epigráficos de colonia Augusta Firma Astigi (Écija, Sevilla)", Zephyrus, 70, 2012, 191-202. 
$\left(C I L I^{2} / 7,285\right)$ es el único personaje del orden ecuestre del que sabemos que fue originario de la colonia. Ya para época de Cómodo, contamos con el testimonio epigráfico excepcional de un uotum pro salute, ceremonia acaso presidida por el gobernador, aunque este extremo no puede certificarse ${ }^{85}$. Pocos años después, la propia ciudad recuerda a varios emperadores en la restauración de sendos edificios, actuaciones que, tal como se hace constar explícitamente, fueron sufragadas por los astigitani ${ }^{86}$. A finales del siglo III d.C. se documenta en la ciudad un procurator Augusti que desempeñó las funciones del gobernador provincial como agens uicepraesidis, sustituyendo probablemente al legado imperial en un momento, a partir de mediados de la centuria, en el que la Baetica había pasado temporalmente a ser provincia imperial ${ }^{87}$. Años más tarde, a mediados del siglo IV d.C., encontramos un anónimo consularis en una inscripción de carácter edilicio, último testimonio conocido por el momento de la presencia activa del poder romano en el centro colonial, y muestra del interés de la ciudad por establecer lazos con personajes notables de la administración imperial ${ }^{88}$. Realmente, los vínculos más evidentes de la ciudad con la estructura imperial y el poder resultan de sus estrechas relaciones con la administración fiscal y annonaria en el ámbito de la economía olearia. En esta esfera, es bien perceptible la existencia de redes supralocales, particularmente las que se establecen a través del corpus de los olearii, con presencia en Hispalis y Roma y los vínculos con la prefectura de la Annona ${ }^{89}$. Astigi supo aprovechar bien, mientras funcionaron, las condiciones que el Estado, como principal motor de la economía imperial, fue creando para atender sus necesidades de abastecimiento, creando mercados interregionales y poniendo en práctica medidas favorecedoras de la producción. En este sentido sí podría decirse que esta colonia es, de una manera muy particular, una "ciudad del poder». Precisamente una de las escasas ocasiones en las que se podrá vislumbrar la implicación activa del poder para con Astigi se desprende de las dos dedicaciones que la Baetica, como prouincia immunis, eleva en la ciudad - y no en Corduba - a mediados del siglo III d.C., justo en el momento en que la

85. HEp 20, 442 = AE 2011, 499; vid. por extenso J. C. Saquete, S. Ordóñez, S. García-Dils, "Una votorum nuncupatio en colonia Augusta Firma (Écija, Sevilla)", ZPE, 176, 2011, 281-290.

86. Se trata en concreto de las denominadas porticus Munatianae y la basilica. Vid. S. García-Dils, S. Ordóñez, "Nueva inscripción edilicia de colonia Augusta Firma Astigi (Écija, Sevilla). Primera evidencia epigráfica de las porticus Munatianae y la basilica", ZPE 194, 2015, 281-289.

87. CIL II $/ 5,1167$. G. Alföldy, "Der Status der Provinz Baetica um die Mitte des 3. Jahrhunderts", en R. Frei Stolba, M. A. Speidel (eds.), RömischeInschriften - Neufunde, Neulesungen und Neuinterpretationen. Festschrift für Hans Lieb, Basel 1995, 29-42.

88. S. Ordóñez, J. C. Saquete, S. García-Dils, "Un gobernador de la Bética en una inscripción edilicia hallada en Astigi”, Epigraphica, 76, 2014, pp. 27-48.

89. S. Ordóñez, "Asociaciones profesionales en Hispania a través de la documentación epigráfica”, en O. Rodríguez, N. Tran, B. Soler (Eds.), Los espacios de reunión de las asociaciones romanas. Diálogos desde la arqueología y la historia, en Homenaje a Bertrand Goffaux, Sevilla 2016, 290-292. Para la presencia de astigitanos en Roma, vid. J. Remesal, "Promoción social en el mundo romano a través del comercio", en F. Marco, F. Pina Polo, J. Remesal Rodríguez (Eds.), Vivir en tierra extraña. Emigración e integración cultural en el mundo antiguo, Barcelona, 2004, 125-136, cit. 130 ss.; añádase ahora el legado M. Vibio Marcelo, vid. J. C. Saquete, "El legado astigitano M. Vibio Marcelo y su muerte en Roma", Veleia, 30, 2013, 143-150. 
economía olearia bética muestra claros signos de agotamiento, patentes especialmente en el cierre de los depósitos del Testaccio ${ }^{90}$. La immunitas recogida en estos textos sería la respuesta imperial a una situación regresiva en la que confluyen procesos que afectan a la estabilidad de las ciudades de la provincia y que, en el caso particular astigitano, se materializan en el abandono de grandes establecimientos industriales de su ager como Las Delicias ${ }^{91}$, en la desaparición de las pequeñas ciudades de la corona colonial y en el consiguiente éxodo rural que termina por densificar la trama urbana de la ciudad.

90. HEp 14, 313-314 = AE 2005, 820-821; P. Sáez, S. Ordóñez, J. C. Saquete, S. García-Dils, “Hispania Baetica, provincia immunis", ZPE, 155, 2005, 299-311.

91. Yacimiento, con el código [41.039.0114] en la Carta Arqueológica Municipal de Écija, que actualmente está siendo objeto de sucesivas campañas de excavaciones bajo la dirección de E. García Vargas, S. Mauné y S. García-Dils. Sobre las primeras intervenciones arqueológicas realizadas en esta conocida alfarería de ánforas Dr. 20, vid. P. Sáez, J. Tinoco, E. García, S. García-Dils, "Excavación arqueológica de urgencia en el alfar romano de Las Delicias (Écija, Sevilla) 1997”, Anuario Arqueológico de Andalucía 1997, vol. III, 562575; vid. además la bibliografía citada supra en n. 58. 